\title{
Review
}

\section{The adult multidisciplinary respiratory neuromuscular clinic}

\begin{abstract}
Many neuromuscular disorders (NMD) are complicated by respiratory failure. These patients are best managed in a multidisciplinary outpatient clinic to provide timely access to the various disciplines they require. The key mainstay of treatment of respiratory failure in patients with NMD is noninvasive ventilation, supported by secretion clearance, speech and language therapy, optimisation of nutrition and the maintenance of mobility. Patients with specific conditions may also require cardiology, neurology, orthopaedics, urology and psychological services. The respiratory NMD multidisciplinary team should also provide access to palliative care, and caregiver health and wellbeing should also be reviewed at clinical reviews. The future of care for the respiratory NMD patient will increasingly involve home services and telehealth and the clinic should be equipped and resourced to deliver these. Although not all health systems will be able to provide all elements of the multidisciplinary team discussed here, this review provides the "ideal" recipe for the adult multidisciplinary team and the evidence base underpinning this from which a clinic can be developed.
\end{abstract}

\section{Educational aims}

- To provide an overview of the care of an adult neuromuscular disorder patient presenting to the multidisciplinary respiratory clinic.

- To provide the evidence base for establishing the different elements of the multidisciplinary respiratory clinic.

\section{Introduction}

Neuromuscular disorders (NMD) include a broad range of neurological diseases that can affect the respiratory system (figure 1). They can include rapidly progressive conditions such as amyotrophic lateral sclerosis (ALS) as well as more slowly progressive or stable conditions such as the inherited muscular dystrophies (table 1). Many forms of NMD can lead to the development of respiratory failure, which
@ERSpublications

Care for neuromuscular-related respiratory failure is complex and is best delivered in a multidisciplinary context. The future will increasingly involve home services and telehealth, and their burden needs to be considered when establishing this service. https://bit.ly/33fNsMT
Cite as: Shah NM, Murphy PB, Kaltsakas G. The adult multidisciplinary respiratory neuromuscular clinic. Breathe 2020; 16: 200121 
Drive

- Opioids/neuropathic agents

- Congenital central hypoventilation syndrome

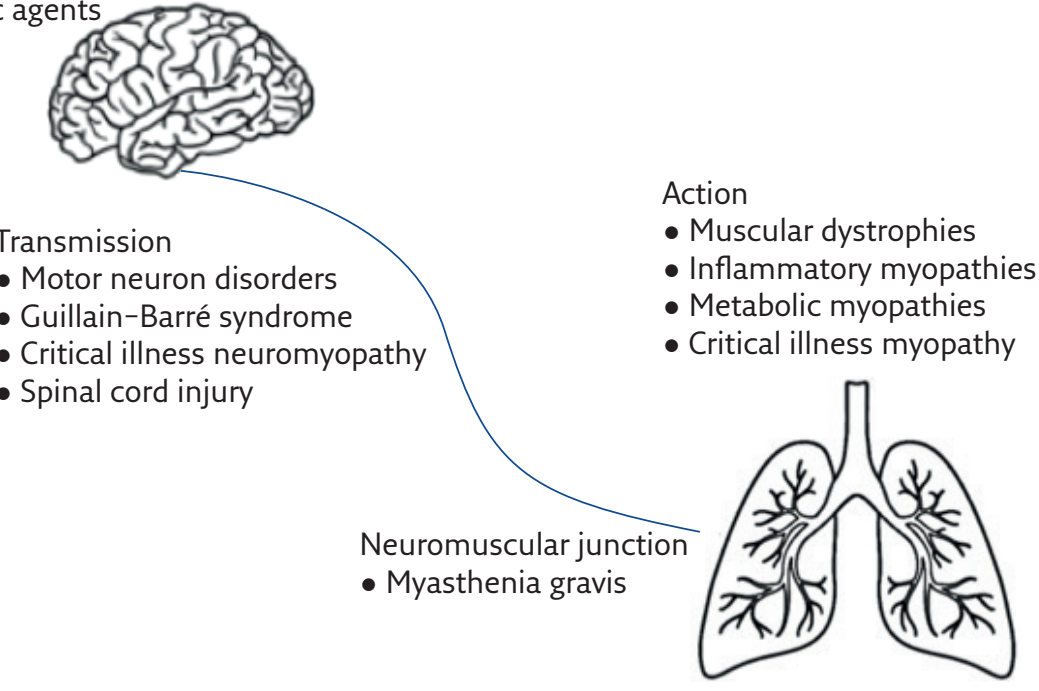

Figure 1 Anatomical distribution of conditions affecting the neuromuscular system that can result in respiratory failure.

contributes to significant impairment of quality of life, morbidity and is often the cause of death [1]. With improving management, the life expectancy of these patients continues to rise, and with increased survival, the prevalence of patients with respiratory morbidity is likely to increase [2]. Monitoring and optimising the respiratory function in these patients is therefore of utmost importance to prolong life and reduce suffering.

The management of NMD patients suffering from respiratory failure is best conducted in a multidisciplinary team (MDT) context, and several disease-specific guidelines, statements and consensus reports recommend that NMD patients should be managed in clinics encompassing all members of the MDT [3-5]. The MDT care model fosters collaborative working across multiple medical specialities and the allied health professions, allowing a patient with multiple complex issues to be supported in a coordinated manner, rather than attending multiple outpatient visits to see different specialists. In fact, studies have demonstrated that not only is the MDT model preferable for patients [6,7], but it also results in improved clinical outcomes when compared to management in a traditional isolated department model [8-10]. A recent publication on patients' experiences of a newly established MDT clinic for ALS reported on the benefits of having patients' care centralised and the confidence that they are seeing clinicians who specialise in their specific disease area. Although some challenges were highlighted (such as the extended travel to a centralised clinic), these were not insurmountable, and the patients in this cohort were generally quite supportive of a transition to the MDT model [11]. This paper will review the make-up of the state-of-the-art multidisciplinary respiratory NMD clinic, the rationale for this make-up and logistical issues that should be considered when developing this model of care.

\section{The multidisciplinary respiratory clinic}

The MDT clinic should consist of a core group of professions that almost all NMD patients will require support from, accompanied by support from other professions who provide care to patients with certain

Table 1 Classification of NMD that most commonly affect the respiratory system

\begin{tabular}{lll}
\hline Rapidly progressive & Variable progression & Slowly progressive or stable \\
\hline Amyotrophic lateral sclerosis & Duchenne muscular dystrophy & Spinal muscular atrophy \\
& Limb girdle muscular dystrophy & Myotonic dystrophy \\
& Myofibrillar myopathy & Post-polio syndrome \\
& Danon disease & Facio-scapulohumeral muscular dystrophy \\
Mitochondrial myopathies & Becker muscular dystrophy \\
& Kennedy disease & Inclusion body myositis \\
& Myasthenia gravis & McArdle disease
\end{tabular}




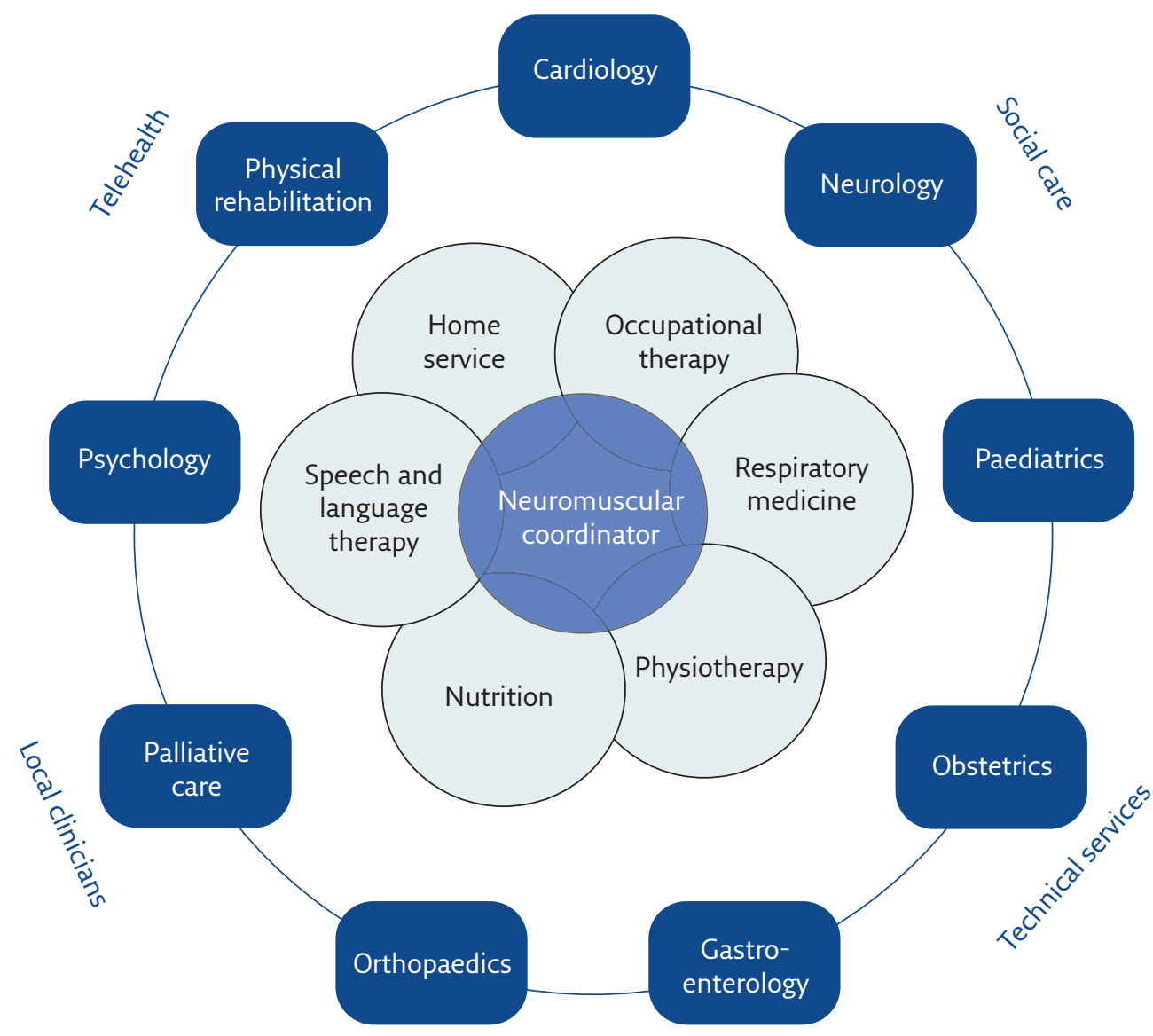

Figure 2 Elements of the neuromuscular respiratory MDT. The inner ring illustrates the specialities that are likely to be physically present in the neuromuscular clinic and considered core to the respiratory neuromuscular MDT, while the outer ring displays specialties that will be consulted and will reach-in to services dependent on specific disease processes.

conditions or those with specific issues (figure 2). The link with community practitioners and services such as palliative care is crucial, and is likely to foster longer periods out of hospital and for the patient to remain at home for as long as possible. The best example of an MDT model of care is arguably in oncology. Oncology MDTs invariably involve an MDT coordinator, responsible for bridging the communication gap between the service provider and the patients [12]. A respiratory NMD MDT would likely benefit from a centralised coordinator to ensure patients are seeing the appropriate services, and only those that actually need to be seen. They would also have a crucial role in managing the contact between patients at home and the clinic, to assure that all remain informed of developments in the patients' care. An alternative approach would be to establish a lead physician and a case manager for each patient, who would ensure that the patient can access the necessary services they need at that time point in the course of their illness [13].

Patients may be referred into the adult NMD respiratory clinic from a number of sources. Neurologists frequently make the diagnosis of neuromuscular conditions and lead on the management of their peripheral nerve dysfunction, as well as administration of disease-modifying agents.
Their input in terms of medical management and prognosis is essential. In many cases, they remain the primary physician managing the care of the patient but are often not co-located with the respiratory clinic; however, usually both neurologists and respiratory physicians jointly manage these patients. Paediatricians will manage all cases of congenital NMD until the time of transition to adult care. Both neurologists and paediatricians will refer to the adult NMD respiratory clinic when their patient exhibits features of respiratory failure for investigation and ongoing management. Some patients will be referred as incident cases of hypercapnic respiratory failure, or respiratory muscle dysfunction of unknown origin for investigation. Others may be referred as part of pregnancy planning [14] or pre-operative assessment [15], if they are considered to be at risk of respiratory muscle weakness during the perioperative period. Any patient referred in to the adult NMD clinic will benefit from a core set of baseline investigations (table 2) [16].

Patients referred from paediatric services must receive specific consideration for the transition to adult care. Barriers to successful transition to adult care include access to specialist adult providers of neuromuscular respiratory care [17], a break in the bond with their long-term paediatric care team [18] 
Table 2 Assessments in the adult multidisciplinary respiratory neuromuscular clinic

\begin{tabular}{|c|c|}
\hline \multirow[t]{5}{*}{ History } & Orthopnoea \\
\hline & Immersion dyspnoea \\
\hline & Daytime somnolence \\
\hline & Impaired cognitive function \\
\hline & Aspiration pneumonia \\
\hline \multirow[t]{3}{*}{ Physical examination } & Use of accessory respiratory muscles \\
\hline & Paradoxical breathing \\
\hline & Tachypnoea (rapid shallow breathing) \\
\hline \multirow{3}{*}{$\begin{array}{l}\text { Gas exchange } \\
\text { assessment }\end{array}$} & Pulse oximetry \\
\hline & Arterial/capillary blood gases \\
\hline & Transcutaneous capnometry \\
\hline \multirow[t]{2}{*}{ Radiological } & Chest radiograph \\
\hline & Diaphragmatic ultrasound \\
\hline \multirow[t]{3}{*}{ Questionnaires } & Epworth Sleepiness Score (ESS) \\
\hline & Sleep-Disordered Breathing in Neuromuscular Disease Questionnaire (SiNQ-5) \\
\hline & Severe Respiratory Insufficiency (SRI) \\
\hline \multirow{5}{*}{$\begin{array}{l}\text { Respiratory muscle } \\
\text { function assessment }\end{array}$} & Spirometry (seated/supine) \\
\hline & Slow vital capacity \\
\hline & Peak cough flow \\
\hline & Maximal mouth inspiratory and expiratory pressure (MIP and MEP) \\
\hline & Sniff nasal inspiratory pressure (SNIP) \\
\hline \multirow{3}{*}{$\begin{array}{l}\text { Advanced respiratory } \\
\text { muscle function } \\
\text { assessment }\end{array}$} & Invasive respiratory muscle assessment (Sniff $\mathrm{P}_{\text {oes }}$ and $\left.\mathrm{P}_{d i}\right)$ \\
\hline & Phrenic nerve stimulation (twitch $\mathrm{P}_{d i}$ ) \\
\hline & Phrenic nerve conduction studies \\
\hline \multirow{4}{*}{$\begin{array}{l}\text { Nocturnal respiratory } \\
\text { function }\end{array}$} & Overnight pulse oximetry \\
\hline & Transcutaneous capnometry (monitoring) \\
\hline & Respiratory polygraphy \\
\hline & Polysomnography \\
\hline
\end{tabular}

Investigations that may provide additional information, but may not be available at all centres are listed in italics.

and changes to financial remuneration policies from paediatrics to adult care. In particular, children receiving ventilation are likely to require a large input from the MDT to ensure a smooth transition to adult care [19]. The US Department of Health and Human Service's Maternal and Child Health Bureau's six core elements of healthcare transition might be a useful model when designing a pathway for paediatric neuromuscular patients to transition to adult services [20].

\section{Ventilation}

A large proportion of NMD patients will require home mechanical ventilation (HMV) at some point during the course of their illness. The initiation and monitoring of HMV are key roles of the respiratory
NMD MDT. Key issues that need to be addressed when organising the MDT include: when long-term ventilation should be started, where it should be initiated, and how it should be monitored. An additional consideration is the assessment of the need to convert to invasive ventilation via tracheostomy.

Patients should be monitored for signs and symptoms of respiratory weakness, prior to initiating HMV. The primary indications for initiating HMV are: 1) respiratory muscle weakness, 2) overnight hypoventilation, and/or 3) symptoms of respiratory muscle weakness during the daytime and/or at night (sleep-disordered breathing) [21]. Daytime hypercapnia ( $>45 \mathrm{mmHg}$ ) is a sign of advanced respiratory muscle weakness and patients referred with this should be treated as urgent cases for initiation of HMV. Indirect 
causes of respiratory muscle weakness, such as congestive cardiac failure, should also be optimised prior to initiation of HMV. Although strong evidence supporting the initiation of HMV prior to the onset of daytime hypercapnia is yet to be published [22, 23], and its impact is likely to be different in different disease groups [24, 25], there are increasing reports of its benefit [26, 27], including prolonging tracheostomy-free survival [28]. Conversely, the presence of bulbar symptoms has been proposed as a reason to delay initiation of noninvasive ventilation (NIV) until the respiratory failure has worsened [29]. There are a number of national and international guidelines that advise on the initiation of $\mathrm{HMV}$ in specific disease groups [27, 30-33].

To investigate for evidence of respiratory muscle weakness, the MDT must have access to a range of investigations (table 2). While respiratory muscle strength is formally assessed using invasive measures of diaphragm weakness, these investigations are invasive, highly specialised and not widely available. There is, therefore, a need for surrogate measures of diaphragmatic weakness. The MDT should be able to conduct spirometry (seated and supine), as well as sniff nasal inspiratory pressure (SNIP), maximal inspiratory (MIP) and maximal expiratory (MEP) pressure. To investigate for daytime hypercapnia and nocturnal hypoventilation, the MDT must have the ability to assess daytime blood gases and organise overnight studies, including overnight oximetry and polysomnography [34]. Screening tools, such as the SiNQ-5 questionnaire can be used during clinic to identify sleep-disordered breathing [35]. Although the ESS is widely used to monitor daytime sleepiness in patients with sleepdisordered breathing, it has low predictive value in patients with neuromuscular conditions [35, 36]. Important disease-specific questionnaires may also be performed in the respiratory NMD clinic. For example, the Amyotrophic Lateral Sclerosis Functional Rating Scale-Revised (ALS-FRS-R) is a useful tool in monitoring the decline in respiratory function in patients with ALS [37].

Traditionally, patients are set-up on NIV during a multi-night inpatient stay, where the NIV is titrated according to polysomnography results [38]. Set-up in outpatient settings has resulted in equivalent adherence to therapy as nocturnal set-up [39] and can avoid the need for admission to hospital. With the advent of auto-titrating devices and telemedicine, there is increasing interest in the validity of remote set-up of NIV. Auto-titrating devices result in similar outcomes to standard devices [40] and home-initiation of NIV is both feasible [41] and noninferior to inpatient-initiation [42]. As devices are improved and the impact of artificial intelligence arrives in respiratory medicine, we are likely to see increasing evidence for the home set-up of NIV [43]. This will add a logistical telemedicine burden to a respiratory NMD MDT, with skilled telemedicine practitioners required to facilitate treatment. It is also important to note that even with remote titration and set-up of the device, an in-person encounter would still be required to determine the optimal interface and provide training on the use of the ventilator; however, this could be done at the patient's home.

Monitoring patients on NIV is important to ensure good adherence and effective treatment. Frequency of monitoring has to be balanced between frequent reviews at the time of initiation, to achieve optimal care, and the need for a disabled individual to come into hospital repeatedly. Once the slowly progressive NMD patient is on stable treatment, annual reviews with daytime gases and nocturnal oximetry are sufficient [44]. Rapidly progressive NMD patients are likely to need more frequent reviews, and with progressive disease, these may require home assessments, emphasising the need for a comprehensive home assessment team as part of the NMD clinic.

The interface used with NIV has considerable impact on outcome. Although the majority of studies investigating the impact of interface have focused on patients with acute respiratory failure [45], two randomised studies in patients with chronic hypercapnic respiratory failure have demonstrated that interface can impact on tolerance to therapy as well as physiological markers of therapy success $[46,47]$. A recent systematic review on NIV in ALS patients has demonstrated the importance of a patient-tailored approach to selection and fitting of the interface to optimise delivery of NIV [48]. Specialists such as respiratory nurses, physiologists and technicians with experience of ventilation are an essential element of the respiratory NMD MDT. They are responsible for ensuring the correct interface is selected to suit the patient's needs and troubleshoot issues with the interface. They will also deliver education and training to patients and carers on applying the NIV mask and using the ventilator. In addition, they would be able to support the detailed interrogation of the data download from the ventilator, which can provide information on adherence, leak, tidal volume and breathing pattern. This information can help optimise treatment at clinic reviews [49, 50], and going forward, will allow remote assessment of ventilation efficacy [51].

Some patients receiving NIV will benefit from conversion to invasive ventilation via tracheostomy [52]. This may include patients with copious secretions despite optimal medical therapy or patients unable to tolerate or achieve satisfactory ventilation. Despite its invasive nature, patients have reported improved breathlessness and fatigue, and better speech and oral intake following tracheostomy [53]. Thus, the MDT will need access to physicians with skills to manage long-term tracheostomised patients. 


\section{Secretion management}

Patients with NMD often suffer from an ineffective cough [54]. This can be due to damage to the innervation of the cough reflex (any of the vagus, phrenic, intercostal or recurrent laryngeal nerves), weakness of inspiratory or expiratory respiratory muscles, inability to close the glottis due to bulbar dysfunction, or any combination of these. Ineffective cough results in inadequate secretion clearance, which can lead to respiratory infections, morbidity and death [55-57]. It is therefore important to support these patients with adequate secretion clearance techniques. Indeed, secretion management is a priority for NMD patients [58].

The presence of a respiratory physiotherapist specialising in neuromuscular diseases in the respiratory NMD MDT would be the gold standard, although it is acknowledged that this may not always be possible in all healthcare systems. Physiotherapy interventions can be divided into proximal and peripheral airway clearance techniques, and different conditions benefit from different techniques. At a minimum, the respiratory NMD MDT should be staffed and equipped to be able to offer manual assisted coughs, mechanical insufflation-exsufflation, lung volume recruitment, glossopharyngeal breathing, and chest wall percussion and oscillation [59]. It is important to note that while it may seem intuitively useful [60] and does not cause any harm [61], there is no convincing evidence for the use of respiratory muscle training to improve clinical outcomes or quality of life in NMD patients [62, 63].

Sialorrhoea is also common in certain NMDs, such as ALS and any condition causing bulbar dysfunction or facial muscle weakness $[64,65]$. Management is important as it can cause skin maceration, psychological difficulties and contribute to intolerance to NIV [66]. Treatment ranges from conservative management, medical therapy with anticholinergics, to surgical therapy. In patients who are refractory to medical management, injection of botulinum toxin into the salivary gland is considered a safe and effective alternative [67-69], with a positive impact on quality of life [70]. Botulinum toxin injections can be safely administered in an outpatient setting, and so practitioners with this skillset would be a valuable addition to the respiratory NMD MDT. In fact, a UK survey of practice of sialorrhoea management identified that the main barrier to the use of botulinum toxin was the availability of trained staff [65]. If botulinum toxin is unsuccessful, contraindicated or unavailable, radiotherapy of the salivary gland is also an option. The literature includes reports of its use in ALS, where it is shown to be successful in effecting an improvement in symptoms for 4-6 months [71, 72]. There appears to be a preference for electron-based therapy compared to photon-based therapy [73]. Surgical options include ligation, denervation, ablation or resection of the salivary glands, but these procedures require a pulmonary reserve, making it unavailable to most NMD patients and infrequently utilised [21].

\section{Cardiovascular care}

Patients with NMD frequently suffer from cardiac disease [74]. The same pathophysiological process causing respiratory muscle weakness can also affect the cardiac myocytes. The prevalence and pattern of cardiac disease varies between different conditions. Some patients will suffer from a dilated cardiomyopathy (e.g. Duchenne muscular dystrophy, Becker muscular dystrophy, limb girdle muscular dystrophy), while others suffer from arrhythmias (e.g. myotonic dystrophy), which can lead to sudden cardiac death [75]. Input from cardiac services for both monitoring and treatment is therefore crucial. Any patient reporting cardiac symptoms, and all patients suffering from conditions that are associated with cardiac dysfunction (the hereditary muscular dystrophies, myotonic dystrophy, mitochondrial disorders and congenital myopathies) $[75,76]$, should be screened regularly with electrocardiograms for arrhythmias [77] and echocardiograms for ventricular dysfunction [76]. It is important to note that the value of echocardiogram decreases with progressive scoliosis and obesity, and so the availability of cardiac magnetic resonance imaging [78] or realtime three-dimensional echocardiography [79] is an important consideration. The availability of a dedicated cardiologist with expertise in NMD in the respiratory NMD MDT would be the gold standard, so that patients can be evaluated and reviewed at the same time. It would also facilitate access to more advanced cardiac interventions such as implantable devices, should the need arise.

\section{Speech and language therapy}

There is a high prevalence of dysarthria and dysphagia in patients with NMD, stemming from respiratory muscle pump, airway muscle and bulbar dysfunction [80]. Although they may be obvious during clinical assessment, the presence of dysphagia correlates well with the presence of dysarthria [81], and so it is important to screen for both. Dysphagia can have a significant impact on nutrition [82] and there is an increased risk of aspiration pneumonia, which can be lifethreatening $[83,84]$. Dysarthria is likely to have a significant impact on an already decreased quality of life [85]. The input of speech and language therapists can have an important impact on the care of these patients. Although the quality of evidence for speech interventions in NMD patients is weak [86], there is no evidence of harm from speech interventions and so it remains a useful 
service to feature in the respiratory NMD MDT. In progressive conditions, patients' speech is likely to deteriorate to a point where verbal communication is not possible. Ensuring access to augmented communication therapies for these individuals is vital to optimise quality of life and health $[87,88]$. In addition, different modes of ventilation impact on speech quality and so close coordination with the respiratory physician is important to ensure that speech is optimised with evolving ventilatory therapies [89].

\section{Nutrition}

Both undernutrition and overnutrition are common issues in the care of patients with NMD. Adequate management of nutrition results in improved quality of life for both patients and their families [3, 90]. Decreased muscle strength causes slow chewing and an increased time to consume food, resulting in reduced oral intake and undernutrition. Patients frequently suffer from delayed gastric emptying (due to gastrointestinal muscle hypotonia), gastrointestinal reflux and constipation [91], which leads to abdominal discomfort and reduced oral intake. In addition, the use of ventilators can lead to swallowing of air, contributing to abdominal discomfort [3]. Overnutrition is a consequence of normal oral intake with reduced caloric need and physical activity or excessive oral intake secondary to appetite-increasing medications, and caregiver compassion preventing caloric restriction [91]. In addition, the introduction of artificial feeding via gastrostomy can result in iatrogenic overnutrition, if not carefully assessed and guided by specialist dieticians. Resulting obesity has implications for longer term cardiovascular and metabolic health, as well as a direct impact on respiratory physiology [92]. It is therefore imperative that the management of NMD patients includes input from dietetic services, ideally in the same clinic location, so that advice can be provided when issues are identified. A study of clinicians caring for ALS patients has highlighted that nutrition can also be impacted by psychological factors, such as distress around the time of diagnosis, the need to maintain control over their own nutritional intake and the loss of social interaction from mealtimes [93]. Clinicians should be mindful of these factors and facilitate access to psychological interventions to support the patient to accept their new nutritional needs and accessibility.

Undernutrition, particularly when secondary to impaired swallowing, can be effectively managed with gastrostomy, inserted surgically, percutaneously or radiologically. This has been demonstrated to reduce the risk of respiratory infections and hospitalisations [94]. Timing of gastrostomy is key; if implemented before the onset of severe respiratory failure, the potential complications of the procedure itself can be minimised [95]. Conversely, there may be psychological issues around maintenance of independence without gastrostomy-nutrition to be considered and so close communication between the gastroenterology team, dietetics and the respiratory team are required to provide optimal nutritional support to the patient.

\section{Physical and occupational therapy, and rehabilitation}

In NMDs there is an element of muscle degradation and so there is long-standing interest in the value of strength-building and rehabilitative interventions on improving quality of life, slowing progression and reducing mortality. Reviews of the existing literature on ALS $[96,97]$ and muscle disorders in general [98] were unable to make conclusive recommendations about the use of physical therapy and rehabilitation interventions. This is primarily due to the heterogeneity of the studies that have been conducted and poor study design. Importantly, no adverse effects of physical therapy have been identified. Furthermore, a synthesis of qualitative data revealed that ALS patients feel rehabilitation interventions result in an improvement in quality of life [99]. As there do not appear to be any negative sequalae, and there are perceived patient-orientated benefits, the MDT should aspire to be able to offer physical therapy to NMD patients. It is acknowledged that in some healthcare systems, the lack of conclusive evidence may result in a difficulty in funding allocation towards this. Physical capability may be augmented with other interventions such as mobility aids, orthotics and abdominal binders. In progressive conditions, patients' mobility may eventually deteriorate such that independent mobilisation is not possible. A dedicated wheelchair service is crucial at this point, particularly if electric powered wheelchairs can be provided, as this will help to maintain some level of independence and reduce the burden on caregivers.

\section{End-of-life considerations}

Palliative care input can provide positive support to patients with NMD, such as the perception of control over their illness, management of troublesome symptoms and future planning [100-102]. Qualitative assessments of patients [103] and bereaved relatives [104] have reported that patients would welcome the input of palliative services, and that otherwise death can involve unmanaged respiratory and psychological symptoms. Despite this, the provision of palliative services is not widespread. In younger people in particular, there appears to be a reluctance from both caregivers and clinicians to initiate conversations about end-of-life care with the 
patient $[105,106]$. The evidence base to support the inclusion of palliative care is sparse [107, 108 ], restricting access to resources. This is partly because, unlike in oncology or COPD, "end-stage" NMD has not been categorically defined [109], leading to clinical challenges about when to introduce palliative care. The perception that the introduction of palliative care leads to cessation of life-prolonging interventions also acts as a barrier, and future models of NMD care should consider palliative care and advanced planning as complementary to life-prolonging therapies, rather than dichotomous [109]. A retrospective review of patients who died within a year of diagnosis of NMD reported that older age at diagnosis, earlyonset breathlessness, dysphagia, constipation and impaired mobility are all significantly associated with early mortality [110], and these criteria could serve as indictors for the introduction of palliative services to an individual's care. Recently, a prognostic model to identify ALS patients at risk of death within 6 months has been published and may be of use in other NMDs [111]. The first report of a joint palliative and NMD service in the UK demonstrated that patients were receptive to this, but that challenges remain around the timing of introducing this service over a patient's disease course [112].

\section{Psychological support}

The presence of psychological disturbance in patients with NMD is well established across many conditions [113-118]. Given that mental health conditions are associated with poorer health outcomes [119], it is likely that they have an important impact on outcomes in NMD patients too. A systematic review on adults with NMD was unable to provide conclusive support for the provision of psychological interventions to improve quality of life; however, this was primarily due to a lack of high-quality evidence [120]. The studies they did identify all reported short-term benefits on quality of life following the introduction of psychological interventions. Indeed, an audit of patient satisfaction after the introduction of a clinical psychologist to a neuromuscular clinic reported not only that patients were supportive and found this useful but also that quantitative measures of wellbeing and satisfaction improved [121]. The provision of psychological support within the respiratory NMD MDT is therefore likely to be beneficial and an important factor in patient-orientated outcomes. There is no evidence-based specialised approach for NMD, particularly because of the varying nature of different NMDs, and so it is important that this provision is staffed by psychologists specialised in the care of NMD patients, who can use their experience to provide a specialised service for this unique cohort [122].

\section{Outreach team and telehealth}

The respiratory NMD MDT is often located at a regional centre, providing care to individuals who come from a large area. Travel to the clinic can be troublesome for the patient, particularly given their mobility limitations and ventilation requirements [11]. A home service, visiting patients in their home, can offset these challenges. A home care team can deliver various functions including clinical review, ventilator servicing, regular tracheostomy tube change, and training of caregivers on equipment use. The MDT should therefore include individuals able to travel to patients' homes or care facilities with the necessary skills-set and equipment to deliver these functions. A recent qualitative study has highlighted the importance of the support a home care team provides, particularly in patients requiring long-term tracheostomy ventilation [123]. The logistics that underpin this service should not be underestimated and financial remuneration for this service will likely require a bespoke system, as "ad hoc" costs are more likely. With centralised care and the increasing survival of NMD patients, the demands on this service are likely to burgeon over the coming years.

The incorporation of telehealth into the MDT model is a potential mutually convenient solution to the travel burden on patients to a centralised clinic and the resource burden of a home service on the MDT. To date, investigations have focused on using telehealth to manage patients ventilated at home. Studies have demonstrated that remote monitoring and adjustment of ventilator settings is feasible [124] and acceptable to patients [125]. When comparing telehealth to usual care, patients receiving telehealth appear to suffer from less emergency room visits and hospitalisations [126, 127] and a lower risk of disease progression [128], although this may reflect a patient selection bias, as those deemed suitable for telehealth may be a healthier cohort. Most of the literature supporting the use of telehealth in NMD reports on cohorts of patients who have been successfully supported via telehealth, without a "usual care" comparator [129-131]. Although not able to demonstrate superiority or equivalence with usual care, they do provide useful descriptions of how telehealth can be implemented in this patient population. An American telehealth service for ALS reported a significant cost reduction compared with standard care [132]; although this will be different in individual health systems, it is likely that once a telehealth service is established, the per-patient cost will be lower by avoiding visits to hospital and possibly reducing the number of investigations. The true value of telehealth is difficult to ascertain without randomised studies; a recent study reported that the feasibility of conducting a randomised trial about telehealth in NMD patients is low [133]. In addition, a review of the evidence supporting the use of telehealth in respiratory illnesses, including NMD, was unable to provide any conclusive findings about its utility [134], even though it appears to 
be acceptable to patients [135]. Nevertheless, as technology advances and patient preferences for interaction with healthcare professionals evolve, particularly with the development of app-based consultations, telehealth is likely to become an important feature of any respiratory NMD MDT.

\section{Burden on caregivers}

Studies in various conditions have reported a significant impact on caregivers' mental health, with a high prevalence of anxiety and depression symptoms [136, 137]. These are often related to: the amount of time spent providing care [136, 138]; the severity of the condition, as well as the emotional health of the patient [139, 140]; isolation due to care commitments [138, 141]; and physical difficulties such as the introduction of a wheelchair [142]. The introduction of HMV adds further burden on caregivers [143], including negatively impacting on carers' sleep quality [144]. Caregivers have reported that they experience a feeling of loss while the patient is still alive, as well as after they have passed away [145]. Psychological support specialised for caregivers of NMD patients would be a useful addition to the MDT to provide interventions when caregivers accompany the patient to clinic. In addition to the impact on caregiver quality of life, the financial burden of caring for NMD patients on families must also be considered [146, 147]. When providing an holistic approach to these patients, it is important to consider the impact on their carers and suggest options to relieve the burden, such as respite care, further education about the care they are providing and signposting to financial assistance, where available. The need for input from social services in the multidisciplinary NMD clinic is clear.

\section{Summary}

The optimal care of a patient with NMD suffering from respiratory failure involves all members of the

\section{Self-evaluation questions}

1. In which of the following settings can NIV be initiated in patients with NMD?
a. inpatient admission with polysomnography
b. outpatient clinic with capnometry
c. home with remote monitoring

2. Which of the following factors have a negative impact on caregiver quality of life?
a. severity of the condition
b. emotional health of the patient
c. introduction of home mechanical ventilation
d. introduction of a wheelchair

3. What cardiovascular complications commonly occur in patients with NMD?
a. cardiomyopathy
b. ischaemic heart disease
c. arrhythmias
d. valvular disorders

4. Which of the following investigations are not part of the assessment of a respiratory NMD patient?
a. respiratory muscle testing
b. overnight oximetry
c. cough assessment
d. cardiopulmonary exercise testing

MDT; the provision of care from each member of the MDT is ideally delivered at the same time in an outpatient clinic where each specialty is co-located. The future of the respiratory NMD MDT will probably rely heavily on telemedicine and home services, and the logistical burden these bring must be considered. Although it is recognised that not all healthcare systems will be able to deliver all of these specialties, and that the requirement will be dependent upon the disease make-up of the clinic population, this review serves as a recipe for the "ideal" multidisciplinary respiratory NMD clinic, from which specific requirements for specific situations can be selected.

\section{Key points}

- Patients with neuromuscular disorders who suffer from respiratory failure require complex care that is best delivered in a multidisciplinary context.

- The core disciplines that most patients will require and that should be available at every clinic include respiratory physicians, physiotherapy, occupational therapy, dietetics, and speech and language therapy.

- The future of the care of the respiratory neuromuscular patient will increasingly involve home services and telehealth, and their burden need to be considered when establishing a service.

- Provision should also be provided for palliative care and support for caregivers. 


\section{Affiliations}

\section{Neeraj M. Shah ${ }^{1,2,3}$, Patrick B. Murphy, ${ }^{1,2,3}$, Georgios Kaltsakas ${ }^{1,2,3}$}

'Lane Fox Respiratory Service, St Thomas' Hospital, Guy's and St Thomas' NHS Foundation Trust, London, UK. 2Lane Fox Clinical Respiratory Physiology Centre, Guy's and St Thomas' NHS Foundation Trust, London, UK. ${ }^{3}$ Centre for Human and Applied Physiological Sciences (CHAPS), King's College London, London, UK.

\section{Conflict of interest}

None declared.

\section{Suggested answers}

1. $a-c$.

2. a-d.

3. a and c. 4. d.

\section{References}

1. Ambrosino N, Carpene N, Gherardi M. Chronic respiratory care for neuromuscular diseases in adults. Eur RespirJ 2009; 34: 444-451

2. Rose L, McKim D, Leasa D, et al. Trends in incidence, prevalence, and mortality of neuromuscular disease in Ontario, Canada: A population-based retrospective cohort study (2003-2014). PLoS One 2019; 14: e0210574.

3. Bushby K, Finkel R, Birnkrant DJ, et al. Diagnosis and management of Duchenne muscular dystrophy, part 2 implementation of multidisciplinary care. Lancet Neurol 2010; 9: 177-189.

4. Kang PB, Morrison L, lannaccone ST, et al. Evidencebased guideline summary: evaluation, diagnosis, and management of congenital muscular dystrophy: Report of the Guideline Development Subcommittee of the American Academy of Neurology and the Practice Issues Review Panel of the American Association of Neuromuscular \& Electrodiagnostic Medicine. Neurology 2015; 84 1369-1378.

5. Miller RG, Brooks BR, Swain-Eng RJ, et al. Quality improvement in neurology: amyotrophic lateral sclerosis quality measures: report of the quality measurement and reporting subcommittee of the American Academy of Neurology. Neurology 2013; 81: 2136-2140.

6. Stephens HE, Felgoise S, Young J, et al. Multidisciplinary ALS clinics in the USA: A comparison of those who attend and those who do not. Amyotroph Lateral Scler Frontotemporal Degener 2015; 16: 196-201.

7. Stephens HE, Young J, Felgoise $\mathrm{SH}$, et al. A qualitative study of multidisciplinary ALS clinic use in the United States. Amyotroph Lateral Scler Frontotemporal Degener 2015; 17: 55-61.

8. Chio A, Bottacchi E, Buffa C, et al. Positive effects of tertiary centres for amyotrophic lateral sclerosis on outcome and use of hospital facilities. J Neurol Neurosurg Psychiatry 2006; 77: 948-950

9. Van den Berg JP, Kalmijn S, Lindeman E, et al. Multidisciplinary ALS care improves quality of life in patients with ALS. Neurology 2005; 65: 1264-1267.

10. RooneyJ, Byrne S, Heverin M, et al. A multidisciplinary clinic approach improves survival in ALS: a comparative study of ALS in Ireland and Northern Ireland. J Neurol Neurosurg Psychiatry 2015; 86: 496-501.

11. Schellenberg KL, Hansen G. Patient perspectives on transitioning to amyotrophic lateral sclerosis multidisciplinary clinics. J Multidiscip Healthc 2018; 11 519-524.

12. Jalil R, Lamb B, Russ S, et al. The cancer multi-disciplinary team from the coordinators' perspective: results from a national survey in the UK. BMC Health Serv Res 2012; 12: 457.

13. Auvin S, Bissler JJ, Cottin V, et al. A step-wise approach for establishing a multidisciplinary team for the management of tuberous sclerosis complex: a Delphi consensus report. Orphanet J Rare Dis 2019; 14: 91.

14. Edmundson C, Guidon AC. Neuromuscular disorders in pregnancy. Semin Neurol 2017; 37: 643-652.
15. Katz JA, Murphy GS. Anesthetic consideration for neuromuscular diseases. Curr Opin Anaesthesiol 2017; 30: $435-440$.

16. Boentert M, Wenninger S, Sansone VA. Respiratory involvement in neuromuscular disorders. Curr Opin Neurol 2017: 30: 529-537.

17. Hill NS. Neuromuscular disease in respiratory and critical care medicine. Respir Care 2006; 51: 1065-1071.

18. Abbott D, Carpenter J, Bushby K. Transition to adulthood for young men with Duchenne muscular dystrophy: research from the UK. Neuromuscul Disord 2012; 22 $445-446$

19. Onofri A, Tan HL, Cherchi C, et al. Transition to adult care in young people with neuromuscular disease on non-invasive ventilation. Ital J Pediatr 2019; 45: 90.

20. Cheng PC, Panitch HB, Hansen-Flaschen J. Transition of patients with neuromuscular disease and chronic ventilator-dependent respiratory failure from pediatric to adult pulmonary care. Paediatr Respir Rev 2020; 33: 3-8.

21. Sahni AS, Wolfe L. Respiratory care in neuromuscular diseases. Respir Care 2018; 63: 601-608.

22. Jacobs TL, Brown DL, Baek J, et al. Trial of early noninvasive ventilation for ALS: A pilot placebo-controlled study. Neurology 2016; 87: 1878-1883.

23. Andersen PM, Abrahams S, Borasio GD, et al. EFNS guidelines on the clinical management of amyotrophic lateral sclerosis (MALS)-revised report of an EFNS task force. Eur J Neurol 2012; 19: 360-375.

24. Dreher M, Rauter I, Storre JH, et al. When should home mechanical ventilation be started in patients with different neuromuscular disorders? Respirology 2007; 12: 749-753.

25. Vitacca M, Banfi P, Montini A, et al. Does timing of initiation influence acceptance and adherence to NIV in patients with ALS? Pulmonology 2020; 26: 45-48.

26. Fauroux $B$, Lofaso F. Non-invasive mechanical ventilation: when to start for what benefit? Thorax 2005; 60: 979-980.

27. Sheehan DW, Birnkrant DJ, Benditt JO, et al. Respiratory management of the patient with Duchenne muscular dystrophy. Pediatrics 2018; 142: Suppl. 2, S62-S71.

28. Lechtzin N, Scott Y, Busse AM, et al. Early use of non-invasive ventilation prolongs survival in subjects with ALS. Amyotroph Lateral Scler 2007; 8: 185-188.

29. Bourke SC, Tomlinson M, Williams TL, et al. Effects of noninvasive ventilation on survival and quality of life in patients with amyotrophic lateral sclerosis: a randomised controlled trial. Lancet Neurol 2006; 5: 140-147.

30. National institute for Health and Care Excellence. Motor neurone disease: assessment and management (NICE Guideline 42). https://www.nice.org.uk/guidance/ng42 Date last updated: 23 July 2019. Date last accessed: 30/06/2020.

31. McKim DA, Road J, Avendano M, et al. Home mechanical ventilation: a Canadian Thoracic Society clinical practice guideline. Can Respir J 2011; 18: 197-215.

32. Miller RG, Jackson CE, Kasarskis EJ, et al. Practice parameter update: the care of the patient with amyotrophic lateral sclerosis: drug, nutritional, and respiratory therapies (an evidence-based review): report of the Quality Standards 
Subcommittee of the American Academy of Neurology. Neurology 2009; 73: 1218-1226.

33. Respiratory care of the patient with Duchenne muscular dystrophy. Am J Respir Crit Care Med 2004; 170: 456-465.

34. Aboussouan LS, Mireles-Cabodevila E. Sleep-disordered breathing in neuromuscular disease: diagnostic and therapeutic challenges. Chest 2017; 152: 880-892.

35. Steier J, Jolley CJ, Seymour J, et al. Screening for sleepdisordered breathing in neuromuscular disease using a questionnaire for symptoms associated with diaphragm paralysis. Eur Respir J 2011; 37: 400-405.

36. Guilleminault C, Philip P, Robinson A. Sleep and neuromuscular disease: bilevel positive airway pressure by nasal mask as a treatment for sleep disordered breathing in patients with neuromuscular disease. J Neurol Neurosurg Psychiatry 1998; 65: 225.

37. Cedarbaum JM, Stambler N, Malta E, et al. The ALSFRS-R: a revised ALS functional rating scale that incorporates assessments of respiratory function. J Neurol Sci 1999. 169: 13-21.

38. Lloyd-Owen SJ, Donaldson GC, Ambrosino N, et al. Patterns of home mechanical ventilation use in Europe: results from the Eurovent survey. Eur Respir J 2005; 25: 1025-1031.

39. Bertella E, Banfi P, Paneroni M, et al. Early initiation of night-time NIV in an outpatient setting: a randomized non-inferiority study in ALS patients. Eur J Phys Rehabil Med 2017; 53: 892-899.

40. Jaye J, Chatwin M, Dayer M, et al. Autotitrating versus standard noninvasive ventilation: a randomised crossover trial. Eur RespirJ 2009; 33: 566-571.

41. Chatwin M, Nickol AH, Morrell MJ, et al. Randomised trial of inpatient versus outpatient initiation of home mechanical ventilation in patients with nocturnal hypoventilation. Respir Med 2008; 102: 1528-1535.

42. Hazenberg A, Kerstjens HAM, Prins SCL, et al. Initiation of home mechanical ventilation at home: A randomised controlled trial of efficacy, feasibility and costs. Respir Med 2014; 108: 1387-1395.

43. Borel JC, Palot A, Patout M. Technological advances in home non-invasive ventilation monitoring: Reliability of data and effect on patient outcomes. Respirology 2019; 24: 1143-1151.

44. Davidescu L, Manolescu D, Ulmeanu R, et al. Noninvasive ventilation in neuromuscular diseases. In: Vats M, ed. Noninvasive Ventilation in Medicine: Recent Updates. London, IntechOpen, 2019. pp. 627-653.

45. Brill A-K. How to avoid interface problems in acute noninvasive ventilation. Breathe 2014; 10: 230.

46. Navalesi P, Fanfulla F, Frigerio P, et al. Physiologic evaluation of noninvasive mechanical ventilation delivered with three types of masks in patients with chronic hypercapnic respiratory failure. Crit Care Med 2000; 28: 1785-1790.

47. Toussaint $M$, Chatwin $M$, Verhulst $S$, et al. Preference of neuromuscular patients regarding equipment for daytime mouthpiece ventilation: A randomized crossover study. Clin RespirJ 2020; 14: 214-221.

48. Brien D, Stavroulakis T, Baxter S, et al. The optimisation of noninvasive ventilation in amyotrophic lateral sclerosis: a systematic review. Eur RespirJ 2019; 54: 1900261.

49. Pasquina P, Pasquina P, Adler D, et al. What does built-in software of home ventilators tell us? An observational study of 150 patients on home ventilation. Respiration 2012; 83 : 293-299

50. Sandoz JS, LeBlanc C, McKim DA. Data downloads for effective noninvasive ventilation in patients with neuromuscular respiratory failure. Respir Care 2014; 59. e35.

51. Mansell SK, Cutts S, Hackney I, et al. Using domiciliary non-invasive ventilator data downloads to inform clinical decision-making to optimise ventilation delivery and patient compliance. BMJ Open Respir Res 2018; 5: e000238

52. Boussaid G, Lofaso F, Santos DB, et al. Impact of invasive ventilation on survival when non-invasive ventilation is ineffective in patients with Duchenne muscular dystrophy: A prospective cohort. Respir Med 2016; 115: 26-32.
53. Khirani S, Ramirez A, Delord V, et al. Evaluation of ventilators for mouthpiece ventilation in neuromuscular disease. Respir Care 2014; 59: 1329-1337.

54. Bach JR. Mechanical insufflation-exsufflation. Comparison of peak expiratory flows with manually assisted and unassisted coughing techniques. Chest 1993; 104: 1553-1562.

55. Tzeng AC, Bach JR. Prevention of pulmonary morbidity for patients with neuromuscular disease. Chest 2000; 118: 1390-1396

56. Rutkowski A, Chatwin M, Koumbourlis A, et al. 203rd ENMC international workshop: respiratory pathophysiology in congenital muscle disorders: implications for pro-active care and clinical research 13-15 December, 2013, Naarden, The Netherlands. Neuromuscul Disord 2015; 25: 353-358.

57. Rahbek J, Steffensen BF, Bushby K, et al. 206th ENMC International Workshop: Care for a novel group of patients adults with Duchenne muscular dystrophy Naarden, The Netherlands, 23-25 May 2014. Neuromuscul Disord 2015; 25: 727-738

58. Bach JR, Campagnolo DI, Hoeman S. Life satisfaction of individuals with Duchenne muscular dystrophy using longterm mechanical ventilatory support. Am J Phys Med Rehabil 1991; 70: 129-135.

59. Chatwin M, Toussaint M, Goncalves MR, et al. Airway clearance techniques in neuromuscular disorders: a state of the art review. Respir Med 2018; 136: 98-110.

60. Williamson E, Pederson N, Rawson $\mathrm{H}$, et al. The effect of inspiratory muscle training on duchenne muscular dystrophy: a meta-analysis. Pediatr Phys Ther 2019; 31: 323-330.

61. Pinto $S$, Swash M, de Carvalho M. Respiratory exercise in amyotrophic lateral sclerosis. Amyotroph Lateral Scler 2012; 13: 33-43.

62. Avendano M, Guell R. [Rehabilitation in patients with neuromuscular and chest wall abnormalities]. Arch Bronconeumol 2003; 39: 559-565

63. Silva IS, Pedrosa R, Azevedo IG, et al. Respiratory muscle training in children and adults with neuromuscular disease. Cochrane Database Syst Rev 2019; 9: CD011711.

64. Hockstein NG, Samadi DS, Gendron K, et al. Sialorrhea: a management challenge. Am Fam Physician 2004; 69: 2628-2634.

65. Hobson EV, McGeachan A, Al-Chalabi A, et al. Management of sialorrhoea in motor neuron disease: a survey of current UK practice. Amyotroph Lateral Scler Frontotemporal Degener 2013; 14: 521-527.

66. Garuti G, Rao F, Ribuffo V, et al. Sialorrhea in patients with ALS: current treatment options. Degener Neurol Neuromuscul Dis 2019; 9: 19-26.

67. Benson J, Daugherty KK. Botulinum toxin A in the treatment of sialorrhea. Ann Pharmacother 2007; 41: 79-85.

68. Formeister EJ, Dahl JP, Rose AS. Surgical management of chronic sialorrhea in pediatric patients: 10-year experience from one tertiary care institution. Int J Pediatr Otorhinolaryngol 2014; 78: 1387-1392.

69. Jackson CE, Gronseth G, Rosenfeld J, et al. Randomized double-blind study of botulinum toxin type $B$ for sialorrhea in als patients. Muscle Nerve 2009; 39: 137-143.

70. Verma A, Steele J. Botulinum toxin improves sialorrhea and quality of living in bulbar amyotrophic lateral sclerosis. Muscle Nerve 2006; 34: 235-237.

71. Neppelberg E, Haugen DF, Thorsen L, et al. Radiotherapy reduces sialorrhea in amyotrophic lateral sclerosis. Eur J Neurol 2007; 14: 1373-1377.

72. Bourry N, Guy N, Achard JL, et al. Salivary glands radiotherapy to reduce sialorrhea in amyotrophic lateral sclerosis: dose and energy. Cancer Radiother 2013; 17: 191-195.

73. Guy N, Bourry N, Dallel R, et al. Comparison of radiotherapy types in the treatment of sialorrhea in amyotrophic lateral sclerosis. J Palliat Med 2011; 14: 391-395.

74. Hermans MCE, Pinto YM, Merkies ISJ, et al. Hereditary muscular dystrophies and the heart. Neuromuscul Disord 2010; 20: 479-492.

75. Sachdev B, Elliott PM, McKenna WJ. Cardiovascular complications of neuromuscular disorders. Curr Treat Options Cardiovasc Med 2002; 4: 171-179. 
76. Feingold B, Mahle WT, Auerbach S, et al. Management of cardiac involvement associated with neuromuscular diseases: a scientific statement from the American Heart Association. Circulation 2017; 136: e200-ee31.

77. Ismail H, Raynor E, Zimetbaum P. Neuromuscular disorders and the role of the clinical electrophysiologist. JACC Clin Electrophysiol 2017; 3: 1069-1079.

78. Brunklaus A, Parish E, Muntoni F, et al. The value of cardiac MRI versus echocardiography in the pre-operative assessment of patients with Duchenne muscular dystrophy. Eur J Paediatr Neurol 2015; 19: 395-401.

79. Tsuburaya RS, Uchizumi H, Ueda M, et al. Utility of realtime three-dimensional echocardiography for Duchenne muscular dystrophy with echocardiographic limitations. Neuromuscul Disord 2014; 24: 402-408.

80. Knuijt S, Kalf JG, de Swart BJM, et al. Dysarthria and dysphagia are highly prevalent among various types of neuromuscular diseases. Disabil Rehabil 2014; 36 1285-1289.

81. Nishio M, Niimi S. Relationship between speech and swallowing disorders in patients with neuromuscular disease. Folia Phoniatr Logop 2004; 56: 291-304.

82. Hill M, Hughes T, Milford C. Treatment for swallowing difficulties (dysphagia) in chronic muscle disease. Cochrane Database Syst Rev 2004; 2: CD004303.

83. Mathieu J, Allard P, Potvin L, et al. A 10-year study of mortality in a cohort of patients with myotonic dystrophy Neurology 1999; 52: 1658-1662.

84. de Die-Smulders CE, Howeler CJ, Thijs C, et al. Age and causes of death in adult-onset myotonic dystrophy. Brain 1998; 121: Pt. 8, 1557-1563.

85. Schröter-Morasch H, Ziegler W. Rehabilitation of impaired speech function (dysarthria, dysglossia). GMS Curr Top Otorhinolaryngol Head Neck Surg 2005; 4: Doc15

86. Knuijt S, Cup EH, Pieterse AJ, et al. Speech pathology interventions in patients with neuromuscular diseases: a systematic review. Folia Phoniatr Logop 2011; 63: 15-20.

87. Ball LJ, Fager S, Fried-Oken M. Augmentative and alternative communication for people with progressive neuromuscular disease. Phys Med Rehabil Clin N Am 2012 23: 689-699.

88. Elsahar Y, Hu S, Bouazza-Marouf K, et al. Augmentative and alternative communication (AAC) advances: a review of configurations for individuals with a speech disability Sensors (Basel) 2019; 19: 1911.

89. Prigent $\mathrm{H}$, Samuel $\mathrm{C}$, Louis B, et al. Comparative effects of two ventilatory modes on speech in tracheostomized patients with neuromuscular disease. Am J Respir Crit Care Med 2003; 167: 114-119.

90. Moore GE, Lindenmayer AW, McConchie GA, et al. Describing nutrition in spinal muscular atrophy: A systematic review. Neuromuscul Disord 2016; 26: 395-404.

91. Davis J, Samuels E, Mullins L. Nutrition considerations in duchenne muscular dystrophy. Nutr Clin Pract 2015; 30 511-521.

92. Shah NMM, Murphy PB. Hypercapnic failure in non-COPD. In: Heunks L, Demoule A, Windisch W, eds. Pulmonary Emergencies (ERS Monograph). Sheffield, European Respiratory Society, 2016; pp. 86-100.

93. Zarotti N, Coates E, McGeachan A, et al. Health care professionals' views on psychological factors affecting nutritional behaviour in people with motor neuron disease: A thematic analysis. Br J Health Psychol 2019 24: 953-969.

94. Ramelli GP, Aloysius A, King C, et al. Gastrostomy placement in paediatric patients with neuromuscular disorders: indications and outcome. Dev Med Child Neurol 2007; 49: 367-371

95. Davidson ZE, Truby H. A review of nutrition in Duchenne muscular dystrophy. J Hum Nutr Diet 2009; 22: 383-393.

96. Lewis $M$, Rushanan S. The role of physical therapy and occupational therapy in the treatment of amyotrophic lateral sclerosis. NeuroRehabilitation 2007; 22: 451-461.

97. Bello-Haas VD. Physical therapy for individuals with amyotrophic lateral sclerosis: current insights. Degener Neurol Neuromuscul Dis 2018; 8: 45-54
98. Voet NB, van der Kooi EL, van Engelen BG, et al. Strength training and aerobic exercise training for muscle disease. Cochrane Database Syst Rev 2019; 12: CD003907.

99. Soofi AY, Bello-Haas VD, Kho ME, et al. The impact of rehabilitative interventions on quality of life: a qualitative evidence synthesis of personal experiences of individuals with amyotrophic lateral sclerosis. Qual Life Res 2018; 27: 845-856.

100. Murray L, Butow PN. Advance care planning in motor neuron disease: A systematic review. Palliat Support Care 2016; 14: 411-432.

101. Murray L, Butow PN, White K, et al. Advance care planning in motor neuron disease: A qualitative study of caregiver perspectives. Palliat Med 2016; 30: 471-478.

102. Andrews JG, Pandya S, Trout $C$, et al. Palliative care services in families of males with muscular dystrophy: Data from MD STARnet. SAGE Open Med 2019; 7: 2050312119840518.

103. Abbott $D$, Prescott $H$, Forbes K, et al. Men with Duchenne muscular dystrophy and end of life planning. Neuromuscul Disord 2017; 27: 38-44.

104. Veigh C M, Donaghy C, Mc Laughlin B, et al. Palliative care for patients with motor neurone disease and their bereaved carers: a qualitative study. BMC Palliat Care 2019; 18: 39.

105. Hiscock A, Kuhn I, Barclay S. Advance care discussions with young people affected by life-limiting neuromuscular diseases: A systematic literature review and narrative synthesis. Neuromuscul Disord 2017; 27: 115-119.

106. Hiscock A, Barclay S. 'It's a hard conversation to have' Healthcare professionals' views concerning advance care discussions with young people affected by life-limiting neuromuscular diseases: an interview study. BMJ Support Palliat Care 2019; 9: e9.

107. de Visser M, Oliver DJ. Palliative care in neuromuscular diseases. Curr Opin Neurol 2017; 30: 686-691.

108. Crimi C, Pierucci P, Carlucci A, et al. Long-term ventilation in neuromuscular patients: review of concerns, beliefs, and ethical dilemmas. Respiration 2019; 97: 185-196.

109. Tripodoro VA, De Vito EL. What does end stage in neuromuscular diseases mean? Key approach-based transitions. Curr Opin Support Palliat Care 2015; 9 : 361-368.

110. Chang RS, Wong YK. Prognostic indicators of neuromuscular disorders for palliative care referral. Ann Palliat Med 2018; 7: 335-338.

111. Ackrivo J, Hansen-Flaschen J, Wileyto EP, et al. Development of a prognostic model of respiratory insufficiency or death in amyotrophic lateral sclerosis. Eur Respir J 2019; 53: 1802237

112. Macfarlane M, Willis TA, Easthope-Mowatt $Y$, et al. Adult neuromuscular disorders: a joint palliative/neuromuscular clinic. BMJ Support Palliat Care 2019; in press [https://doi. org/10.1136/bmjspcare-2019-001821].

113. Mori-Yoshimura M, Mizuno Y, Yoshida S, et al. Psychiatric and neurodevelopmental aspects of Becker muscular dystrophy. Neuromuscul Disord 2019; 29: 930-939.

114. Travlos V, Patman S, Wilson A, et al. Quality of life and psychosocial well-being in youth with neuromuscular disorders who are wheelchair users: a systematic review. Arch Phys Med Rehabil 2017; 98: 1004-1017.

115. Hogg KE, Goldstein LH, Leigh PN. The psychological impact of motor neurone disease. Psychol Med 1994 24: 625-632

116. Bernsen RA, de Jager AE, Kuijer W, et al. Psychosocial dysfunction in the first year after Guillain-Barre syndrome. Muscle Nerve 2010; 41: 533-539.

117. Merkies ISJ, Kieseier BC. Fatigue, pain, anxiety and depression in Guillain-Barré syndrome and chronic inflammatory demyelinating polyradiculoneuropathy. Eur Neurol 2016; 75: 199-206.

118. Andrews JA, Paganoni S, Braastad C et al. Disease burden in upper motor neuron syndromes: a survey of patient perspectives. J Clin Neuromuscul Dis 2014; 16: 104-105.

119. Walker ER, McGee RE, Druss BG. Mortality in mental disorders and global disease burden implications: a systematic review and meta-analysis. JAMA Psychiatry 2015; 72: 334-341 
120. Walklet E, Muse K, Meyrick J, et al. Do psychosocial interventions improve quality of life and wellbeing in adults with neuromuscular disorders? A systematic review and narrative synthesis. J Neuromuscul Dis 2016; 3: 347-362.

121. Easthope-Mowatt $Y$, Kulshrestha R, Willis T. Clinical psychology provision in the neuromuscular team. Neuromuscul Disord 2015; 25: S242.

122. Rabbitte M, Bates U, Keane M. Psychological and psychotherapeutic approaches for people with motor neuron disease: A qualitative study. Amyotroph Lateral Scler Frontotemporal Degener 2015; 16: 303-308.

123. Amar-Dolan LG, Horn MH, O'Connell B, et al. "This is how hard it is": Family experience of hospital-to-home transition with a tracheostomy. Ann Am Thorac Soc 2020; 17: 860-868

124. Vitacca M, Assoni G, Pizzocaro P, et al. A pilot study of nurseled, home monitoring for patients with chronic respiratory failure and with mechanical ventilation assistance. J Telemed Telecare 2006; 12: 337-342.

125. Portaro S, Calabro RS, Bramanti P, et al. Telemedicine for FacioScapulo-Humeral Muscular Dystrophy: A multidisciplinary approach to improve quality of life and reduce hospitalization rate? Disabil Health J 2018; 11: 306-309.

126. Pinto A, Almeida JP, Pinto S, et al. Home telemonitoring of non-invasive ventilation decreases healthcare utilisation in a prospective controlled trial of patients with amyotrophic lateral sclerosis. J Neurol Neurosurg Psychiatry 2010; 81: 1238-1242.

127. Vitacca M, Bianchi L, Guerra A, et al. Tele-assistance in chronic respiratory failure patients: a randomised clinical trial. Eur Respir J 2009; 33: 411-418.

128. Selkirk SM, Washington MO, McClellan F, et al. Delivering tertiary centre specialty care to ALS patients via telemedicine: a retrospective cohort analysis. Amyotroph Lateral Scler Frontotemporal Degener 2017; 18: 324-332.

129. Vitacca M, Comini L, Assoni G, et al. Tele-assistance in patients with amyotrophic lateral sclerosis: long term activity and costs. Disabil Rehabil Assist Technol 2012; 7: 494-500.

130. Henderson RD, Hutchinson N, Douglas JA, et al. Telehealth for motor neurone disease. Med J Aust 2014; 201: 31

131. Zamarrón C, Morete E, González F. Telemedicine system for the care of patients with neuromuscular disease and chronic respiratory failure. Arch Med Sci 2014; 10: 1047-1051.

132. Paganoni S, van de Rijn M, Drake K, et al. Adjusted cost analysis of video televisits for the care of people with amyotrophic lateral sclerosis. Muscle Nerve 2019; 60: 147-154.

133. Hobson EV, Baird WO, Bradburn M, et al. Using telehealth in motor neuron disease to increase access to specialist multidisciplinary care: a UK-based pilot and feasibility study. BMJ Open 2019; 9: e028525.

134. Ambrosino N, Fracchia C. The role of tele-medicine in patients with respiratory diseases. Expert Rev Respir Med 2017; 11: 893-900.

135. Helleman J, Kruitwagen ET, van den Berg LH, et al. The current use of telehealth in ALS care and the barriers to and facilitators of implementation: a systematic review. Amyotroph Lateral Scler Frontotemporal Degener 2020; 21 : 167-182.

136. Landfeldt E, Lindgren P, Bell CF, et al. Quantifying the burden of caregiving in Duchenne muscular dystrophy. J Neurol 2016; 263: 906-915.

137. Kurauchi G, Endo M, Odaira K, et al. Caregiver burden and related factors among caregivers of patients with myotonic dystrophy type 1. J Neuromuscul Dis 2019; 6: 527-536.

138. Holkham L, Soundy A. The experience of informal caregivers of patients with motor neurone disease: A thematic synthesis. Palliat Support Care 2018; 16: 487-496.

139. Gluyas C, Mathers S, Hennessy Anderson N, et al. Factors to consider for motor neurone disease carer intervention research: A narrative literature review. Palliat Support Care 2017; 15: 600-608.

140. de Wit J, Bakker LA, van Groenestijn AC, et al. Caregiver burden in amyotrophic lateral sclerosis: A systematic review. Palliat Med 2018; 32: 231-245.

141. Cremers CH, Fischer MJ, Kruitwagen-van Reenen ET, et al. Participation and mental well-being of mothers of homeliving patients with spinal muscular atrophy. Neuromuscul Disord 2019; 29: 321-329.

142. Pousada T, Groba B, Nieto-Riveiro L, et al. Determining the burden of the family caregivers of people with neuromuscular diseases who use a wheelchair. Medicine (Baltimore) 2018; 97: e11039.

143. Evans R, Catapano MA, Brooks D, et al. Family caregiver perspectives on caring for ventilator-assisted individuals at home. Can Respir J 2012; 19: 373-379.

144. Nozoe KT, Polesel DN, Moreira GA, et al. Sleep quality of mother-caregivers of Duchenne muscular dystrophy patients. Sleep Breath 2016; 20: 129-134.

145. Anderson $\mathrm{NH}$, Gluyas $\mathrm{C}$, Mathers $\mathrm{S}$, et al. "A monster that lives in our lives": experiences of caregivers of people with motor neuron disease and identifying avenues for support. BMJ Support Palliat Care 2019; 9: e27.

146. Landfeldt E, Lindgren P, Bell CF, et al. The burden of Duchenne muscular dystrophy: an international, crosssectional study. Neurology 2014; 83: 529-536.

147. Teoh LJ, Geelhoed EA, Bayley K, et al. Health care utilization and costs for children and adults with duchenne muscular dystrophy. Muscle Nerve 2016; 53: 877-884. 